\title{
Doctor of nursing practice students advocating for health care access, quality, and reform: from the virtual classroom to capitol hill.
}

Mary Lou Manning

Thomas Jefferson University

Dolores Grosso

Thomas Jefferson University

Follow this and additional works at: https://jdc.jefferson.edu/nursfp

Part of the Nursing Commons

Let us know how access to this document benefits you

\section{Recommended Citation}

Manning, Mary Lou and Grosso, Dolores, "Doctor of nursing practice students advocating for health care access, quality, and reform: from the virtual classroom to capitol hill." (2011).

College of Nursing Faculty Papers \& Presentations. Paper 33.

https://jdc.jefferson.edu/nursfp/33

This Article is brought to you for free and open access by the Jefferson Digital Commons. The Jefferson Digital Commons is a service of Thomas Jefferson University's Center for Teaching and Learning (CTL). The Commons is a showcase for Jefferson books and journals, peer-reviewed scholarly publications, unique historical collections from the University archives, and teaching tools. The Jefferson Digital Commons allows researchers and interested readers anywhere in the world to learn about and keep up to date with Jefferson scholarship. This article has been accepted for inclusion in College of Nursing Faculty Papers \& Presentations by an authorized administrator of the Jefferson Digital Commons. For more information, please contact: JeffersonDigitalCommons@jefferson.edu. 


\title{
As submitted to:
}

\author{
Journal of Nursing Education
}

\author{
And later published as:
}

\section{Doctor of Nursing Practice Students Advocating for Health Care Access, Quality, and Reform: From the Virtual Classroom to Capitol Hill}

\author{
Vol. 50, No. 1, 2011, pp.14-20. \\ doi:10.3928/01484834-20101029-05
}

Mary Lou Manning, PhD, CRNP; and Dolores Grosso, DNP, CRNP

\begin{abstract}
The potential for doctor of nursing practice students to inform and influence the national health care reform movement inspired faculty teaching an online Health and Social Policy course to create an assignment combining comparative effectiveness research with a trip to Capitol Hill to meet with congressional representatives. Preparing for and participating in such an assignment can present challenges for online doctoral students already busy with family and professional responsibilities. However, from both faculty and student perspectives, the lasting value and professional growth are immeasurable. Course details and the theoretical concepts of experiential education are presented, as well as trip logistics and evaluation.
\end{abstract}

Doctor of nursing practice (DNP) graduates must be politically astute and strategically engaged in health care policy development, analysis, implementation, and evaluation. These activities by DNP graduates are critical to ensure that their advanced practice experience and requisite knowledge are recognized and used to advance policies that promote health care access, quality, and cost effectiveness. The American Association of Colleges of Nursing (AACN), in The Essentials of Doctoral Education for Advanced Nursing Practice, states: 
Political activism and a commitment to policy development are central elements of professional nursing practice, and the DNP graduate has the ability to assume a broad leadership role on behalf of the public as well as the nursing profession. (Ehrenreich, as cited in AACN, 2006, p. 13)

The DNP students enrolled in an online Health and Social Policy course at our school of nursing had the unique opportunity to experience health care policy for advocacy in health care from multiple vantage points, culminating in a trip to Capitol Hill to meet with congressional representatives and their legislative aides. This article describes how experiential learning, based in current national health care reform events, facilitated DNP students' acquisition of key advocacy skills that they will integrate into their advanced practice roles.

\section{Course Background}

Our school of nursing began offering a post-master's DNP distance education program in 2007 and 2 years later received accreditation from the Commission on Collegiate Nursing Education. The Health and Social Policy, 15-week asynchronous online course was offered for the second time during the summer of 2009. Six advanced practice nurses (APNs), with clinical expertise spanning acute care, primary care, and organization of care, were enrolled in the course; four were employed in the Philadelphia region and two were workplace colleagues from rural Pennsylvania. The students had completed 8 of the 12 required courses (most of the courses they had taken together), making them experienced with distance education, Blackboard (the online learning sys tem), discussion boards, library resources and services, and effective mechanisms for contact and dialogue with peers and faculty. Students were also acclimated to the teaching and learning shift from teacher-directed to student-centered learning (Misch, 2002).

The faculty member assigned to the course focused on assisting students in learning by establishing the learning environment, setting boundaries, providing information and resources, posing questions, selecting meaningful experiences, guiding reflection, providing feedback, and functioning as course facilitator, coach, and mentor (Avery, Ringdahl, Juve, \& Plumbo, 2003; Itin, 1999). Faculty communicated with students almost daily via online chats, e-mail, telephone, teleconference, and requested face-to-face meetings.

The course assignment readings, PowerPoint ${ }^{\circledR}$ presentations combined with an audio component, video clips, and related discussion boards helped students acquire a working knowledge of policy development and analysis, advocacy models, the history of health care law as it relates to current advanced nursing practice, the delivery and financing of health care, and the related ethical and social justice implications. Readings such as the critically acclaimed Mama Might Be Better Off Dead: The Failure of Health Care in Urban America (Abraham, 1993) provided students a profound look at the human face of health care, and Senator Daschle's Critical: What We Can Do About the Health Care Crisis (2008) furnished additional insights to help students examine the primary barriers to quality-based, universal health care for all Americans, as well as the proposals to address these barriers in the context of the current health care debate. 
The high-impact health reform nursing message Commitment to Quality Reform: A Consensus Statement from the Nursing Community (2009) containing solution recommendations to improve access, cost, and quality also was discussed and critiqued. Students subscribed to the online Kaiser Health News Daily Health Policy Report (www.kaisernetwork.org), and they also followed the legislative session in their home state to better understand the impact of proposed, pending, and approved legislation. Students were expected to explore the Web sites listed in the Table to identify legislators' interests and committee assignments.

Realizing the historic moment of the national health care reform movement and the potential impact that the DNP students had to influence health policy, a new assignment combining a comparative effectiveness policy brief with the experience of "A Day on Capitol Hill" to engage legislators was added as a course requirement. Students were informed of the requirement on the first day of class via the online course board and eagerly arranged their work schedules to accommodate a planned trip to Washington, DC. The faculty member responsible for the course, who was experienced in making Capitol Hill visits, created the itinerary and contacted congressional offices to schedule appointments. The first appointment was scheduled with Deborah Trautman, PhD, RN, a Robert Wood Johnson Health Policy Fellow and an aide to U.S. House Speaker Nancy Pelosi. All of the students lived or worked in Pennsylvania, so subsequent meetings were scheduled with the offices of U.S. Senators Robert Casey and Arlen Specter as well as U.S. Representative Robert Brady (representative for constituents in the First

Congressional District where the college of nursing is located). The Capitol Hill visit was made during the 13th week of the course.

\section{Experiential Education}

Experiential education is a philosophy and methodology in which educators purposefully engage learners in direct experience and targeted reflection to increase knowledge, develop skills, and clarify values (Association for Experiential Education, n.d.). The purpose is to stimulate inquiry and skill in the process of knowledge acquisition, and the emphasis is on the process of learning rather than behavioral outcomes (Kolb, 1984). Reflection has considerable power in enabling individuals to change work practices and personal beliefs, and mentoring has been identified as a vehicle to facilitate reflection (Ehrich, Hansford, \& Tennent, 2004).

Experiential education involves a transaction or interaction between learners, between learners and teachers, and between learners and the environment. It is an ideal medium for application and reinforcement of information learned through didactic coursework (Kolb, 1984). Batalden and Davidoff (2007) consider experiential education a vehicle for going beyond conceptual knowledge (knowing that) to the acquisition of working knowledge (knowing how). This form of active learning is grounded in adult learning theory and promotes learner-centered and lifelong learning (Itin, 1999; Kolb, 1984).

A search of the nursing education literature revealed that the majority of published literature relates to experiential learning rather than the broader theoretical concept of 
experiential education and was focused primarily on the traditional planned clinical instructional experience in baccalaureate nursing education. Undergraduate clinical instruction allows students to spend significant time in actual practice settings under the supervision and guidance of practicing professionals to learn how to apply knowledge and gain skills in clinical judgment while caring for patients (Hanson \& Stenvig, 2008; Hickey, 2010). Human patient simulation, a technique of experiential learning, has garnered greater acceptance in nursing education, especially for advanced clinical training such as critical care and emergency care (Schiavenato, 2009). Hedger (2008) describes Web-based education in graduate nursing programs and calls for expanding the opportunities that are available to learners to create rich learning environments for teaching both mechanical and qualitative skill.

DNP students possess considerable expertise in their specialty area and as such understand how health policy affects the lives of patients, families, nurses, and the health care system itself. They are rightfully concerned with the issues of clinical care quality, cost, and access to care (Ridenour \& Trautman, 2009). The emphasis on evidence-based practice is apparent throughout the DNP curriculum and facilitated by the addition of well-placed, meaningful experiences and targeted reflection that increase knowledge, develop skills, and clarify values, and more specifically in this course, relate to knowledge-based actions to improve health care by influencing policy decisions at the local, state, and federal levels. Offering experiential educational opportunities provides doctoral students a stage to practice policy dialogue; engage in actions that influence health policy; and participate in patient, community, and societal advocacy (Spenceley, Reutter, \& Allen, 2006; Taft \& Nanna, 2008).

\section{Visit Preparation}

Comparative effectiveness research was under careful scrutiny by Congress, the White House, and federal agencies; therefore, it was appropriate to add comparative effectiveness research as a focus for the Health and Social Policy course (Ridenour \& Trautman, 2009). This was especially timely because President Obama's stimulus plan earmarked $\$ 1.1$ billion for research that compares the effectiveness of different medical options, and \$300 million was appropriated in the American Recovery and Reinvestment Act of 2009 for the Agency for Healthcare Research and Quality (AHRQ) to fund comparative effectiveness research for a 2-year period (AHRQ, 2010).

According to the AHRQ (n.d.), comparative effectiveness research is designed to inform health care decisions by providing evidence on the effectiveness, benefits, and harm of different treatment options. The evidence is generated from research studies that compare drugs, medical devices, tests, surgeries, or ways to deliver care. The core question of comparative effectiveness research is which treatment or intervention works best for whom and under what circumstances. The challenge of comparative effectiveness research is getting the right information to the right people at the right time (Coopey, James, Lawrence, \& Clancy, 2008).

One component of comparative effectiveness research is the evaluation of optimal provider types or combinations of providers in delivering quality, cost-effective care. 
Because legislation regarding a national comparative effectiveness program is in its earliest stages, it is imperative that all DNP graduates understand the importance of incorporating strategies to examine and evaluate APN-based care now so that future analyses of efficacy and cost effectiveness can include this health care provider group.

In preparation for the Capitol Hill visits, students were asked to imagine themselves as DNP graduates serving as health policy fellows in Washington, DC, for their U.S. senators. In the imagined capacity, the senators had asked them to prepare two comparative effectiveness research policy briefs. The first brief was to compare care provided by APNs in nurse-run community-based clinics with other health care providers related to access, quality, and cost, and the second brief was to compare the effect of reimbursement for service between nurse practitioners (NPs) and physicians. A policy brief is a short, neutral summary of what is known about a public problem. Briefs synthesize a large amount of complex detail so that a legislator can easily understand the heart of the issue, its background, the stakeholders, and any recommendations about the future of the issue. Comparative effectiveness readings, Web sites, resources, and policy brief examples were added as a folder to the online course board for the students. Concurrently, a comparative effectiveness resource room discussion board was launched as a place for students to post and discuss helpful resources that they discovered.

Students' produced eloquent policy briefs that demonstrated how health care provided by APNs is effective in terms of quality and cost in a multitude of areas including:

- Mental health (Southern, Leahey, Harper-Jaques, McGonigal, \& Syverson, 2007). 1 Primary care (Brown, Brown, \& Jones, 1979; Laurant et al., 2004; Mundinger et al., 2000).

- Hypertension and obesity (Ramsay, McKenzie, \& Fish, 1982).

- HIV management (Aiken et al., 1993).

Students discovered that there are approximately 250 nurse-managed health centers (NMHCs) operating nationwide, with 2.5 million patient encounters annually. In the students' home state of Pennsylvania, 40 such clinics provide care to more than 200,000 people. The clinics serve as safety net providers for patients without the ability to access care (Hansen-Turton, Line, O'Connell, Rothman, \& Lauby, 2004) and provide urgent care, thereby decreasing the cost of emergency room visits (Southern et al., 2007). Inspired by the powerful evidence, the students decided, and the faculty member agreed, that a goal of their Capitol Hill experience would be to ask their legislators to support passage of two bills seeking increased NMHC funding, namely, the House of Representatives (H.R.) Bill 2754, Nurse-Managed Health Clinic Investment Act of 2009, and the corresponding Senate (S.) Bill 1104, the Nurse-Managed Health Clinic Investment Act of 2009.

The topic of the second brief, comparing APN and physician reimbursement, produced equally compelling data. Students' discovered that the evolutions of APN reimbursement and autonomy are correlated with each other and have impacts on health care access, cost, and quality. Lack of reimbursement was identified as a barrier to the use of NPs for 
health promotion as early as 1986 (Office of Technology Assessment). The reimbursement of APNs by Medicare was recommended in the Physician Payment Review Commission's 1989 annual report to Congress (Morrow, 1992), and the Omnibus Budget Reconciliation Act (1990) provided direct reimbursement to NPs in rural areas. Subsequently, the Balanced Budget Act (1997) granted direct Medicare reimbursement of NPs regardless of the setting at $85 \%$ of the physician rate. Despite gains in the area of reimbursement, barriers such as the inability to directly bill Medicare at $100 \%$ of the physician rate for services and the lack of recognition and reimbursement by private insurers still remain (Hansen-Turton, Ritter, \& Torgan, 2008). Disparities in recognition and reimbursement for APNs due to government and private insurer policies have also decreased the ability of APNs to operate financially sustainable clinics (Hansen-Turton et al., 2004), an issue linked directly to sustainability of the NMHCs.

Via discussion boards and teleconference, the students and faculty discussed and reflected on the findings and agreed to combine the two equally important and related issues (passage of H.R. Bill 2754 and S. Bill 1104, and support for APN reimbursement and autonomy) as the primary advocacy focus for the Capitol Hill visits. In turn, the students, with the help of faculty, distilled their policy briefs to a one-page "ask" document that succinctly described the problem, potential solutions, recommendations for action, and their contact information. The one-page ask paper was to be handed to the congressional staff member at the conclusion of each meeting.

\section{Visit Logistics}

During the first week of class, a Washington, DC, visit logistics folder was added to the online course board containing specific specific information related to student travel, dress and congressional meetings. The folder contained information about the visit including travel, dress, and meetings.

\section{$\underline{\text { Travel }}$}

Students were responsible for making their own travel arrangements and to pay their own expenses. Faculty provided train information and driving directions, and stressed the importance of being punctual for the first scheduled meeting.

\section{$\underline{\text { Dress }}$}

How students present themselves on Capitol Hill can be almost as important as how they present their ideas. Students were required to wear business attire and to wear comfortable shoes. Students were also reminded that they would go through a metal detector in each building and to take that into consideration when they dressed for the day. Identification with students' photographs would also be required when entering each building.

\section{Meetings}

Meetings on Capitol Hill happen in a variety of settings and can vary widely in duration. Students were reminded that they needed to: 
- Be able to deliver their message in 3 or 10 minutes. Although meetings generally are scheduled for 45 to 60 minutes, less or more time may be allotted depending on Capitol Hill activity for that day.

- Be prepared to talk about themselves and their work, and most importantly, the reason for their meeting. Students were instructed to focus on why NMHCs matter, not what they are, and to refrain from using any acronyms or jargon. Students were instructed to be able to clearly and concisely describe the reasons for their meeting and to practice relaying their message.

- Be prepared to tell strategic stories. A well-developed, purposeful story is an effective and compelling way to emotionally connect members of Congress to the reason for the meeting and help them understand how the topic affects the lives of their constituents. A strategic story can transform a polite listener into an engaged champion of an issue.

- Bring copies of their one-page ask papers, preferably on colored paper, to leave after each meeting. Ultimately, that sheet of paper may be the only document congressional staff will keep after the meetings.

- Bring a supply of business cards. The Washington protocol is to exchange cards at the beginning of the meeting.

- Bring a camera. Students were told not to be shy to take advantage of photo opportunities.

- Make it happen. The success or failure of the meeting is determined by quick follow-up after the meeting. Students were instructed to write a thank you letter outlining the different points covered during the meeting and to send along any additional information and materials requested.

\section{A Day on Capitol Hill}

The faculty member and the students traveled to Washington by train. The train ride provided the opportunity for students to get better acquainted, share and discuss their one-page ask papers, and practice their policy skills. After arriving at the Capitol, the faculty and students cleared security and proceeded to their meeting with Dr. Trautman. The faculty member introduced Dr. Trautman, who in turn asked the students to introduce themselves and to explain the purpose of their visit to Washington. Dr. Trautman provided students with a brief overview of "life on the Hill," the current health care reform climate, and the role of nursing.

As the DNP students began to discuss the current health care policy initiatives in relation to their positions as patient advocates, they validated that the language of much of the proposed legislation was exclusionary of APNs and other health care providers. For example, H.R. Bill 2824, the Doctor-Patient Relationship and Research Protection Act (2009), was recently introduced to administer and support federally funded comparative effectiveness research relating to health care. The bill specifies the membership of at least three physicians on a federal coordinating council for comparative effectiveness research without a similar requirement for other health care providers. The reality is that patient care is often provided by a team of health care professionals, and APNs in particular have played essential roles in care delivery. This concept, the provision of the optimal team for the best outcomes, is a goal of comparative effectiveness 
research, and policy should be more inclusive to reflect this growing reality. Therefore, scrutiny of policy language to reflect new realities became one of the students' unanticipated points for advocacy. The meeting with Dr. Trautman ignited student interest in the importance of nurses' involvement in public policy and political processes (Gebbie, Wakefield, \& Kerfoot, 2000).

Next, the group went to the Cannon House Building on the south side of the Capitol to meet with the legislative correspondent for Representative Brady. The primary purpose of the visit was to thank Representative Brady for co-sponsoring H.R. 2754 and to discuss the related issue of APN reimbursement. Students also discussed H.R. 2824 and advocated for the addition of APNs on the coordinating council for comparative effectiveness research.

After lunch, the group proceeded to the north side of the Capitol to meet with the legislative correspondent for Senator Arlen Specter in the Hart Senate Office Building and then with the legislative correspondent for Senator Robert Casey in the Russell Senate Office Building. With each visit, the students gained greater confidence, concisely answered questions, articulated their "ask," identified the next steps, volunteered to provide requested follow-up materials, and exchanged business cards.

At the conclusion of the final visit, the group debriefed and separated. Within moments of departure, two of the students encountered Senator Casey and engaged him in dialogue, telling him who they were, why they were there, and asked him directly to support S.B. 1104. The students surprised themselves with the clarity of their message and learned first-hand the need to be ready for chance encounters with policymakers.

\section{Student Reflections}

The first meeting with Dr. Trautman centered not only on the importance of the nursing voice in health policy formation but also on the requirement for nursing leaders to avoid insular concerns that reduce the quality of the nursing message. For nurses to effectively assume a principal role in health care issues, leaders should be cognizant of the impression they are making about their profession in public forums. Thus, nurses should promote a comprehensive, interprofessional approach to health care reform and avoid the trap of publicly discussing areas of intraprofessional controversy best addressed by nurses alone. This advice was invaluable in the ensuing meetings with the legislative correspondents.

The legislative correspondents were exceptionally polished and professional despite their obvious youth. They possessed an admirable working knowledge of the proposed health care legislation moving through their division of Congress, although they lacked familiarity with health care policy as it pertained to nursing as well as the role that NMHCs could play in alleviating problems with access to health care for patients. As a result, the students found that they had to educate as well as advocate. Students used strategic stories about their patients and their roles in caring for them to help familiarize the legislative correspondents with advanced practice nursing. Students also had the opportunity to discuss the identified issues of proposed legislation for NMHCs and comparative effectiveness. The purpose of these discussions was to provide information 
and ask for assistance in passing legislation that would support the students' position on these issues. Emphasis was placed on linking the real benefits of such legislation to constituents in the district and state that the members of Congress represented. Interestingly, the legislative correspondents welcomed and were grateful to receive the students' one-page ask papers.

Discussing this proposed legislation with the legislative correspondents presented opportunities to both educate them about the role of advanced practice nursing in health care and to inform them about the contributions nurses could make toward alleviating the current problems of access to quality primary care. The students learned firsthand the need for nurses in the practice arena to develop policy partnerships as well as the value policymakers place on nursing's voice to inform health policy conversations. The addition of this well-planned, experiential learning trip to the nation's Capitol, enriched by faculty dialogue and mentoring, provided an extraordinary opportunity to actively participate in direct advocacy and the political process.

\section{Faculty Reflections}

Online classes for doctoral students, already busy with family and professional commitments and responsibilities, make using teaching strategies that require direct political and policy participation challenging to plan and implement. However, with minimal advanced notification, the six students in this Health and Social Policy course were remarkably willing and enthusiastic to make the necessary arrangements to participate in what they viewed as a meaningful learning experience and an opportunity to spend time with fellow DNP students and faculty. This may have been because students were all geographically located within several hours of Washington and travel was relatively easy and inexpensive. The students took full advantage of the experience, beginning during the train ride with sharing their policy briefs with one another and rehearsing their messages, to equally sharing the stage during each congressional visit. The students were well prepared, poised, and articulate. The student-faculty postvisit debriefing and reflection lead to the writing of this article.

Course evaluation is critical to curricular and DNP program success (Graff, Russell, \& Stegbauer, 2007). Student evaluation indicated that online delivery of the Health and Social Policy course was not a barrier. The doctoral students overwhelmingly related that this online class was rigorous and challenging, producing deep and lasting professional and personal growth. One student wrote how she now valued the importance of building relationships with policymakers for anyone working to bring about social change, and another student noted how the experience with advocacy would encourage her to work harder in the future on behalf of her patients and her profession. Another indicator of success is the online chatter that the course has generated among students who will be taking the online course next—-they want to "go to Washington too."

Logistically, scheduling the legislative visits, especially during the summer when so many legislators were not in Washington, was time consuming. Flexibility and patience were essential. Surprisingly, the Washington trip was not viewed as inconvenient or onerous, because as one student wrote they "knew months in advance" and because it was the "only such event throughout the curriculum." An important lesson is that 
experiential education strategies can be successfully used in online DNP programs to meet course objectives, but such strategies must be timely, purposeful, and well planned. Although student-faculty experiential trips to Washington may not be feasible for many DNP programs, smaller scale individual or group trips could be planned to school boards, county seats, city hall, or state capitols.

\section{Implications}

For the students, taking the Health and Social Policy course during this unprecedented time of health care reform was both provocative and exciting. However, advocacy for patients and profession is a critical ongoing role for all nurses regardless of whether health care policy is the current subject of the national news. By virtue of their advanced training and experience, DNP students and graduates are obligated to assume leadership roles in the promotion of health care policy that supports and expands the recognition of nurses as providers of quality care. DNP students should be cognizant of the need for their profession to speak in a united voice with attention to both the content of the message and the context in which the message is delivered. Nurses will only be viewed as major players in health care policy formation by adopting a global, interprofessional stance.

Current legislative proposals such as those that increase funding for NMHCs provide a methodology to increase access to quality primary care in a relatively rapid manner. DNP students and graduates should work to publicly support this legislation and inform their nursing peers of the importance of political activity regarding this issue. Comparative effectiveness legislation provides an opportunity to define the role of the APN in providing quality, cost-effective care across all health care settings.

Despite a limited time frame, the DNP students were able to discuss all of their advocacy points during each congressional visit. The ability to distill complex issues into brief but effective communications is a necessity for DNP students and an important skill that was honed during their educational program. The trip to Capitol Hill provided a framework for the students' developing roles as leaders in health care policy development, analysis, implementation, and evaluation, and created an atmosphere of collegiality among the students.

\section{References}

Abraham, L.K. (1993). Mama might be better off dead: The failure of health care in urban America. Chicago, IL: University of Chicago Press.

Agency for Healthcare Research and Quality. (2010). AHRQ and the Recovery Act. Retrieved from http://www.ahrq.gov/fund/cefarra.htm

Agency for Healthcare Research and Quality. (n.d.). What is comparative effectiveness research? Retrieved from http://www.effectivehealthcare.ahrq.gov/index.cfm/what-iscomparative-effectiveness-research1/ 
Aiken, L.H., Lake, E.T., Semaan, S., Lehman, H.P., O'Hare, P.A., Cole, C.S., et al. (1993). Nurse practitioner managed care for persons with HIV infection. Image-The Journal of Nursing Scholarship, 25, 172-177.

American Association of Colleges of Nursing. (2006). The essentials of doctoral education for advanced nursing practice. Retrieved from http://www.aacn.nche.edu/DNP/pdf/Essentials.pdf

Association for Experiential Education. (n.d.). What is experiential education? Retrieved from http://www.aee.org/membership/background

Avery, M.D., Ringdahl, D., Juve, C., \& Plumbo, P. (2003). The transition to web-based education: Enhancing access to graduate education for women's health providers. Journal of Midwifery \& Women's Health, 48, 418-425.

Balanced Budget Act of 1997, Pub. L. No. 105-33, § 4511. (1997).

Batalden, P., \& Davidoff, F. (2007). Teaching quality improvement: The devil is in the details. Journal of the American Medical Association, 298, 1059-1061.

Brown, J.D., Brown, M.I., \& Jones, F. (1979). Evaluation of a nurse practitioner-staffed preventive medicine program in a fee-for-service multispecialty clinic. Preventive Medicine, 8, 53-64.

Commitment to quality health reform: A consensus statement from the nursing community. Solutions for improving access, cost, and quality. (2009). Retrieved from the American Association of Colleges of Nursing Web site: http://www.aacn.nche.edu/Government/pdf/ConsensusStmnt.pdf

Coopey, M., James, M.D., Lawrence, W., \& Clancy, C. (2008). The challenge of comparative effectiveness: Getting the right information to the right people at the right time. Journal of Nursing Care Quality, 23, 1-5.

Daschle, T. (2008). Critical: What we can do about the health-care crisis. New York, NY: St. Martin's Press.

Doctor-Patient Relationship and Research Protection Act of 2009, H.R. 2824, 111th Cong. (2009).

Ehrich, L.C., Hansford, B., \& Tennent, L. (2004). Formal mentoring programs in education and other professions: A review of the literature. Educational Administration Quarterly, 40, 518-540.

Gebbie, K.M., Wakefield, M., \& Kerfoot, K. (2000). Nursing and health policy. Journal of Nursing Scholarship, 32, 307-315. 
Graff, J.C., Russell, C.K., \& Stegbauer, C.C. (2007). Formative and summative evaluation of a practice doctorate program. Nurse Educator, 32, 173-177.

Hansen-Turton, T., Line, L., O'Connell, M., Rothman, N., \& Lauby, J. (2004). The nursing center model of health care for the underserved. Retrieved from National Nursing Centers Consortium Web site: http://www.nncc.us/research/CMSRevisedExecutiveSummary-120604.doc

Hansen-Turton, T., Ritter, A., \& Torgan, R. (2008). Insurers' contracting policies on nurse practitioners as primary care providers: Two years later. Policy, Politics, \& Nursing Practice, 9, 241-248.

Hanson, K.J., \& Stenvig, T.E. (2008). The good clinical nursing educator and the baccalaureate nursing clinical experience: Attributes and praxis. Journal of Nursing Education, 47, 38-42.

Hedger, A. (2008). Web-based education in graduate nursing programs. Clinical Scholars Review, 1, 121-124.

Hickey, M.T. (2010). Baccalaureate nursing graduates' perceptions of their clinical instructional experiences and preparation forpractice. Journal of Professional Nursing, 26, 35-41.

Itin, C.M. (1999). Reasserting the philosophy of experiential education as a vehicle for change in the 21st century. The Journal of Experiential Education, 22, 91-98.

Kolb, D.A. (1984). Experiential learning: Experience as the source of learning and development. Upper Saddle River, NJ: Prentice Hall.

Laurant, M., Reeves, D., Hermens, R., Braspenning, J., Grol, R., \& Sibbald, B. (2004). Substitution of doctors by nurses in primary care (Article No. CD001271). Cochrane Database of Systematic Reviews, Issue 4.

Misch, D.A. (2002). Andragogy and medical education: Are medical students internally motivated to lean? Advances in Health Sciences Education, 7, 153-160.

Morrow, M.M. (1992). Medicare physician payment reform: Implications for nurse practitioners. Journal of the American Academy of Nurse Practitioners, 4, 38-43.

Mundinger, M.O., Kane, R.L., Lenz, E.R., Totten, A.M., Tsai, W.Y., Cleary, P.D., et al. (2000). Primary care outcomes in patients treated by nurse practitioners or physicians: A randomized trial. Journal of the American Medical Association, 283, 59-68.

Nurse-Managed Health Clinic Investment Act of 2009, H.R. 2754, 111th Cong. (2009).

Nurse-Managed Health Clinic Investment Act of 2009, S. 1104, 111th Cong. (2009). 
Office of Technology Assessment. (1986). Nurse practitioners, physician assistants, and certified nurse-midwives: a policy analysis (Health Technology Case Study 37, OTAHCS-37). Retrieved from http://www.fas.org/ota/reports/8615.pdf

Omnibus Reconciliation Act of 1990, Pub. L. No. 101-508. (1990).

Ramsay, J.A., McKenzie, J.K., \& Fish, D.G. (1982). Physicians and nurse practitioners: Do they provide equivalent health care? American Journal of Public Health, 72, 55-57.

Ridenour, N., \& Trautman, D. (2009). A primer for nurses on advancing health reform policy. Journal of Professional Nursing, 25, 358-362.

Schiavenato, M. (2009). Reevaluating simulation in nursing education: Beyond the human patient simulator. Journal of Nursing Education, 48, 388-394.

Southern, L., Leahey, M., Harper-Jaques, S., McGonigal, K., \& Syverson, A. (2007). Integrating mental health into urgent care in a community health centre. Canadian Nurse, 103, 29-34.

Spenceley, S.M., Reutter, L., \& Allen, M.N. (2006). The road less traveled: Nursing advocacy at the policy level. Policy, Politics, \& Nursing Practice, 7, 180-194.

Taft, S.H., \& Nanna, K.M. (2008). What are the sources of health policy that influence nursing practice? Policy, Politics, \& Nursing Practice, 9, 274-287.

\begin{tabular}{|c|c|}
\hline \multicolumn{2}{|l|}{ TABLE } \\
\hline What to Know & Where to Find It \\
\hline Members of Congress & http://www.house.gov/writerep \\
\hline \multicolumn{2}{|l|}{ Legislative interests and passions } \\
\hline $\begin{array}{l}\text { Most members seek elected office because they care about something-an } \\
\text { issue, a region of the country, something job related; knowing these interests } \\
\text { can help tailor requests and find common ground to build relationships }\end{array}$ & $\begin{array}{l}\text { http://www.house.gov } \\
\text { http://www.senate.gov } \\
\text { http://thomas.loc.gov }\end{array}$ \\
\hline \multicolumn{2}{|l|}{ Committee assignments } \\
\hline $\begin{array}{l}\text { The committees that members of Congress are assigned to are a measure of } \\
\text { their interests in a particular topic, as well as their ability to supply needed } \\
\text { support and advice in those policy areas }\end{array}$ & $\begin{array}{l}\text { House assignments: http://clerk.house.gov } \\
\text { Senate assignments: http://senate.gov }\end{array}$ \\
\hline Voting history & http://thomas.loc.gov \\
\hline \multicolumn{2}{|l|}{ Party affiliation } \\
\hline $\begin{array}{l}\text { Knowing the party affiliation of elected officials may provide a sense of their } \\
\text { perspective of the world }\end{array}$ & $\begin{array}{l}\text { House assignments: http://clerk.house.gov } \\
\text { Senate assignments: http://senate.gov }\end{array}$ \\
\hline \multicolumn{2}{|l|}{ Personal interests: } \\
\hline $\begin{array}{l}\text { Often, a member's personal interests or background can be as helpful as their } \\
\text { professional interests }\end{array}$ & $\begin{array}{l}\text { Scanning members' biographies for hobbies, } \\
\text { memberships, and other background that may help } \\
\text { establish a connection on a personal level }\end{array}$ \\
\hline
\end{tabular}

